\title{
Assessment of MELCOR condensation models with the presence of noncondensable gas in natural convection flow regime
}

\author{
Dhongik S. Yoon, HangJin Jo, Michael L. Corradini \\ Department of Engineering Physics, University of Wisconsin, Madison WI, 53705
}

\begin{abstract}
Condensation of steam vapor is an important mode of energy removal from the reactor containment. The presence of noncondensable gas complicates the process and makes it difficult to model. MELCOR, one of the more widely used system codes for containment analyses, uses the heat and mass transfer analogy to model condensation heat transfer. To investigate previously reported nodalization-dependence in natural convection flow regime, MELCOR condensation model as well as other models are studied. The nodalization-dependence issue is resolved by using physical length from the actual geometry rather than node size of each control volume as the characteristic length scale for MELCOR containment analyses. At the transition to turbulent natural convection regime, the McAdams correlation for convective heat transfer produces a better prediction compared to the original MELCOR model. The McAdams correlation is implemented in MELCOR and the prediction is validated against a set of experiments on a scaled AP600 containment. The MELCOR with our implemented model produces improved predictions. For steam molar fractions in the gas mixture greater than about 0.58 , the predictions are within the uncertainty margin of the measurements. The simulation results still underestimate the heat transfer from the gas-steam mixture, implying that conservative predictions are provided.
\end{abstract}

Keywords: condensation model, noncondensable gas, natural convection, MELCOR

\section{Introduction}

In a postulated design basis accident scenario in a light water reactor (LWR) where high pressure steam escapes into the containment, the temperature and pressure in the containment must be kept under 
the design limits in order to maintain the integrity of the structure. Therefore, the ability to predict the temperature-pressure response in the containment in such case is an important concern.

Condensation, due to the magnitude of heat transfer associated with phase change and passive nature of the phenomenon, can always be considered as an energy removal mechanism in the containment. In the case of accidents, the vapor would initially condense on the surface by forming condensate droplets on the dry surface. This drop-wise condensation, however, is not expected to persist and characterize the whole containment (Slaughterbeck, 1970) and will quickly change to film-wise condensation in high heat flux scenarios typically encountered in a LWR (Corradini, 1983). Therefore, this paper only considers film-wise condensation.

In current containment designs, air is present in the containment and, with the potential of the accident to go beyond its design basis, hydrogen gas could be produced by metal oxidation. This presence of noncondensable gas in a vapor can have a significant effect on condensation heat transfer (Othmer, 1929). Because the cold wall is impermeable, noncondensable gas builds up near the condensing surface acting as another layer of resistance to mass transfer. The condensation rate, directly related to the interfacial steam fraction, also decreases accordingly.

Since the original analysis on the film-wise condensation of Nusselt (1916), analytical models for predicting condensation in the presence of a noncondensable gas has been developed. Sparrow (1964) devised a model based on conservation laws alone using liquid and vapor-gas boundary layers approach. Kim (1990) studied the effect of two-dimensional flow by solving the conservation equations with k- $\varepsilon$ model for turbulence. The concept of effective condensation thermal conductivity was introduced by Peterson (1993) based on diffusion layer theory for turbulent condensation. This concept was extended by Herranz (1998) and Liao (2007) to produce improved predictive results in specific conditions or to be applied in wider range of circumstances. 
While the analytical models offer first-principle based solutions, obtaining the actual solutions usually requires large iterations in a computational framework. Phenomenological models, on the other hand, provide significantly less-sophisticated models that still produces reasonable solutions. Chilton and Colburn (1934) developed a condensation model based on heat and mass transfer analogy (HMTA). Corradini (1983) derived a condensation model for turbulent condensation including both natural and forced convection by extending Reynolds-Colburn analogy. A more complete list and assessments of different formulations of HMTA can be found in Ambrosini's work (2006). To improve the predictions using this analogy, one can use the concept of the suction factor (Bird et al., 2002) to account for the concentration difference at the condensing surface and the bulk. Kutateladze (1979) suggested a film rippling correction factor addressing the enhancement of heat transfer due to the waviness of laminar condensate film.

Due to the simplicity and its computationally-inexpensive nature, models based on HMTA have been incorporated into reactor systems codes, such as RELAP5-3D and MELCOR. These codes hold advantages for complete system analyses as they integrate different components of the nuclear power plant and are able to predict the transient progression of accidents in the plant as a whole. Fu (2015) studied the condensation models used by RELAP5-3D and MELCOR and concluded that the model incorporated into RELAP5-3D had errors that may make its prediction unreliable. Hence this paper only considers MELCOR as the analysis tool for steam condensation.

$\mathrm{Fu}$ (2015) assessed MELCOR codes with Anderson's condensation experiment (1998) in natural convection flow regime and concluded that the prediction of MELCOR is reasonable but the predicted heat removal rate is largely dependent on the nodalization. Anderson's experiment, conducted on a scaled containment of the Westinghouse's AP600 pressurized water reactor, acts as a bridge to close the gap between the large scale experiments and small scale separate effects studies by addressing conditions similar to those expected during the accidents in the actual PWRs; facility with comparable aspect ratio, similar surface finishes, experimental conditions, etc. (Anderson, 1998). Therefore, it is expected that the 
temperature-pressure response, one of the key parameters for containment analyses, of Anderson's facility may be comparable to that of the actual containment.

Enhancing the accuracy of MELCOR prediction is of great interest as it is one of the more widely used system codes for containment analyses for a range of accident conditions. In this paper, MELCOR condensation model as well as other widely used condensation models are assessed with Anderson's experiment as the benchmark. Our primary objective is to evaluate the reported nodalization-dependent predictions and to implement appropriate heat transfer models in MELCOR 2.1.

\section{Description of Benchmark Experiment}

Anderson's (1998) atmospheric experiments are used as the benchmark experiment against which the MELCOR's predictions are validated in this paper. The scaled experimental facility (1:12 linear scale) is a representation of the containment of the AP600. The atmospheric test section, in which the pressure is maintained at the atmospheric pressure throughout the experiment, is a rectangular vessel with dimensions of approximately $2.4 \mathrm{~m}$ tall, $1.4 \mathrm{~m}$ wide and $0.3 \mathrm{~m}$ in depth. The test vessel has two $0.91 \mathrm{~m}$ long condensing plates attached to it: one oriented vertically and the other horizontally. Superheated steam (about 1.72 bars and $125{ }^{\circ} \mathrm{C}$ ) is injected from the bottom representing released steam during accidents. The condensing walls are kept cold by running cooling water on the back-side through cooling plates. All other parts of the test vessels are insulated. The temperature difference between wall and internal bulk atmosphere along with a concentration difference caused by removal of steam species due to condensation induces a natural circulation flow in the vessel (Anderson, 1998). The experiments were conducted under steady-state conditions.

The heat transfer coefficients (HTC) were determined using two independent methods: local heat flux measurements (HFM) and coolant energy balance (CEB). The HFM method utilizes a linear array of thermocouples embedded in the cooling plates and calculates HTC for each plate by Fourier's law. 
$h_{H F M}=\frac{k_{w}(d T / d x)}{T_{b}-T_{w}}$

The CEB method obtains the overall HTC by calculating the heat gain of the coolants running on the back side of the condensing plates.

$h_{C E B}=\frac{\left(\rho C_{p} \dot{V} \Delta T\right)_{c}}{A\left(T_{b}-T_{w}\right)}$

The error for the local measurements was approximately $10 \%$ for both methods and the relative error between them was approximately $15 \%$. A more complete description of the experiment can be found in the reference literature.

\section{Modeling of Experiment}

The control volume representations of the experimental test vessel used for MELCOR simulation is show in Fig. 1. The section directly attaching two condensing walls is isolated and the rest of the vessel is divided in two columns to allow natural circulation currents. The former part was either taken as a whole control volume (Fig. 1 (a)) or divided finely to test for nodalization-dependence (Fig. 1 (b)). Similar nodalizations were also used for the analysis by Fu (2015) that resulted in nodalization-dependent predictions.

MELCOR requires characteristic length scale input in addition to basic geometry information for heat transfer calculation. The nodalization-dependent predictions outlined by $\mathrm{Fu}$ (2015) were from MELCOR simulations assuming the size of the control volumes as the characteristic length input. To further investigate this issue, both physical length of the condensing plate and the node sizes were considered for the characteristic length scale input. For the one-volume nodalization, the physical length of the plate and the node size of the control volume are equal, but this is not the case for the grid nodalization. 
According to the test protocol, the desired temperature and pressure of the test vessel (and so the steady state condition) was set by manually adjusting the steam flowrate (Anderson, 1998). Therefore, the exact inlet flowrate is not known and the simulations were conducted on a trial and to achieve the simulated steady state conditions in the test vessel. First, preliminary simulations were performed with experimental steady state conditions as the initial conditions for the simulation. The steam injection rates for the preliminary simulations (guess value) were calculated according to the following expression:

$\dot{m}_{\text {guess }}=\frac{\left(h_{V}+h_{H}\right)\left(T_{b}-T_{w}\right) A}{\Delta H_{v}}$

From the results of the preliminary simulations, the injection rates were adjusted to meet the experimental steady state conditions. The simulations were considered to have reached steady state when the bulk pressure of the vessel was maintained at approximately 1 bar and the heat removal rates through the condensing plates were constant. Typical pressure-temperature response for MELCOR simulation is shown in Fig. 2. The complete list of experimental and simulation steady state conditions is provided in Table 1.

Anderson's experiment included two condensing plates, one vertical and one horizontal, with about $20 \%$ higher heat flux through the horizontal plate (Anderson, 1998). In the case of cold horizontal plate facing down, one would expect the steam to diffuse faster through the noncondensable gas layer because air is heavier than steam vapor. Limited growth of condensate film with condensate dripping on the horizontal wall would also help cause a higher heat flux through the wall although the effect is of second order. This paper considers heat and mass transfer on vertical wall only to illustrate the nodalization results. The horizontal downward facing condition is being analyzed.

\section{Condensation Models}

\subsection{MELCOR}


MELCOR obtains mass transfer coefficient for condensation from the Nusselt number by a heat and mass transfer analogy using equation 4 and 5 (Gauntt et al., 2005).

$$
\begin{aligned}
& S h=N u S c^{1 / 3} \operatorname{Pr}^{-1 / 3} \\
& j_{\text {cond }}=S h \frac{D}{L}
\end{aligned}
$$

The type of convective heat transfer at the fluid-solid surface is determined from relative magnitudes of Grashof number and Reynolds number. MELCOR assumes natural convection if the Grashof number is greater than the square of Reynolds number. For all tests, natural convection was confirmed as predicted by Anderson (1998). MELCOR assumes laminar if the Rayleigh number falls below $10^{9}$, turbulent if above $10^{10}$ and transition in between. Rayleigh numbers for Anderson's experiments were calculated to be in the order of $10^{9}$ and $10^{10}$. This indicates that MELCOR considered the cases to be transition and turbulent flows depending on the steam molar fraction. Corresponding Rayleigh numbers for Anderson's experiments are shown in Fig. 3.

For natural convection heat transfer with rectangular geometry and external flow, MELCOR uses Churchill-Chu correlation (equation 6 and 7) to obtain convective heat transfer. In the case of transition, MELCOR calculates Nusselt number for both laminar and turbulent cases and obtains transition Nusselt number by linear interpolation based on Rayleigh number (equation 8).

$$
\begin{array}{ll}
N u_{\text {laminar }}=0.59 R a^{1 / 4}=0.59(\operatorname{GrPr})^{1 / 4} & R a<10^{9} \\
N u_{\text {turbulent }}=0.10(\mathrm{GrPr})^{1 / 3} & R a>10^{10} \\
N u_{\text {transition }}=N u_{\text {laminar }}+\left(\frac{R a-10^{9}}{10^{10}-10^{9}}\right)\left(N u_{\text {turbulent }}-N u_{\text {laminar }}\right) & 10^{9} \leq R a \leq 10^{10}
\end{array}
$$

Grashof number defined below includes $\mathrm{L}^{3}$ term and Prandtl number is independent of $\mathrm{L}$. Because the equation 6 for obtaining laminar Nusselt number raises Grashof number to $1 / 4$ power, the Sherwood number, proportional to Nusselt number, then includes $\mathrm{L}^{3 / 4}$ term. 
$G r \equiv \frac{g\left|\rho_{i}-\rho_{b}\right| \rho_{b} L^{3}}{\mu^{2}}$

Therefore, the condensation mass transfer coefficient for laminar flow now includes $\mathrm{L}^{-1 / 4}$ term and is length scale-dependent according to equation 5 while the condensation mass transfer coefficient for turbulent flow is independent of characteristic length scale. In turbulent regime where the condensation mass transfer coefficient is calculated from both laminar and turbulent Nusselt number, the condensation rate and therefore the condensation heat flux are then length scale-dependent due to the contribution from the laminar expression.

$$
\begin{aligned}
& j_{\text {cond,laminar }}=\frac{0.59 G r^{1 / 4} S c^{1 / 3} \operatorname{Pr}^{-1 / 12} D}{L}=0.59\left(\frac{k_{b}}{\rho_{b} c_{p, b}}\right)^{1 / 12}\left(\frac{g\left|\rho_{i}-\rho_{b}\right|}{\mu_{b} L}\right)^{1 / 4} D^{2 / 3} \propto L^{-1 / 4} \\
& j_{\text {cond,turbulent }}=\frac{0.10 G r^{1 / 3} S c^{1 / 3} D}{L}=0.10\left(\frac{g\left|\rho_{i}-\rho_{b}\right|}{\mu_{b}}\right)^{1 / 3} D^{2 / 3} \propto L^{0} \\
& j_{\text {cond,transition }}=j_{\text {cond,laminar }}+\left(\frac{R a-10^{9}}{10^{10}-10^{9}}\right)\left(j_{\text {cond,turbulent }}-j_{\text {cond,laminar }}\right)
\end{aligned}
$$

It should be noted that heat and mass transfer analogy assumes fully developed turbulent flow (Chilton and Colburn, 1934). However, MELCOR makes no distinction between laminar and turbulent flow in applying this analogy (Gauntt et al., 2005).

The suction effect proposed by Bird (2002) is included in terms of logarithmic ratio of partial pressures (Gauntt, 2005).

$$
\dot{m}_{\text {cond }}^{\prime \prime}=j_{\text {cond }} \rho_{v, b} \ln \left(\frac{P_{b}-P_{v, i}}{P_{b}-P_{v, b}}\right)
$$

\subsection{Diffusion model}

A self-consistent diffusion model was separately developed. This model recognizes the layer of noncondensable gas near the condensing surface through which the steam vapor must diffuse in order to 
condense. The heat and mass transfer analogy is also assumed to predict condensation mass transfer from convective heat transfer expression. Additionally the following assumptions were made to establish the model: 1) laminar condensate film, 2) constant film properties, 3) negligible gas velocity, 4) shear free liquid-gas interface, 5) no slip at the wall, 6) negligible convection effects in the film, 7) no radiative heat transfer, and 8) natural convection flow regime. This model also includes a suction factor outlined by Bird (2002) and a film rippling correction factor proposed by Kutateladze (1979).

To describe natural convection heat transfer, McAdams correlation was used (Rohsenow and Choi, 1961). With heat and mass transfer analogy, mass transfer coefficient is determined by the following set of expressions and is length scale-independent.

$$
\begin{aligned}
& N u=0.13(G r P r)^{1 / 3} \\
& S h=0.13(G r S c)^{1 / 3} \\
& j_{\text {cond }}=\Theta S h \frac{D}{L}=\Theta \frac{0.13 G r^{1 / 3} S c^{1 / 3} D}{L}=0.13\left(\frac{g\left|\rho_{i}-\rho_{b}\right|}{\mu_{b}}\right)^{1 / 3} D^{2 / 3} \Theta
\end{aligned}
$$

Suction factor in the form of following expression is included (Bird et al., 2002):

$$
\begin{aligned}
& \Theta=\frac{\ln (1+B)}{B} \\
& B=\frac{Y_{v, i}-Y_{v, b}}{1-Y_{v, i}}=\frac{Y_{n, b}-Y_{n, i}}{Y_{n, i}}
\end{aligned}
$$

Film rippling correction factor enhances the condensate film HTC based on film Reynolds number (Kutateladze, 1979):

$$
\begin{aligned}
& h_{f}=h_{f}^{*} \cdot R e_{f}^{0.04} \\
& R e_{f}=\frac{4 \Gamma}{\mu_{f}}
\end{aligned}
$$




\subsection{Model comparison}

The film rippling correction factor (Kutateladze, 1979) is not included in MELCOR model. For the given test conditions, including this correction factor enhances the film HTC by $3 \sim 11 \%$. However, the factor enhances the heat transfer in the film condensate region whereas the condensation heat transfer is the rate limiting heat transfer process as illustrated in Fig 4. When the noncondensable gas is present, $h_{f}$ is greater than $h_{\text {cond }}$ and $h_{\text {conv }}$ by $2 \sim 3$ orders of magnitude. Therefore, small enhancement of HTC in film does not significantly affect the overall HTC.

$h_{\text {overall }}=\left(\frac{1}{h_{f}}+\frac{1}{h_{\text {cond }}+h_{\text {conv }}}\right)^{-1}=\frac{h_{f}\left(h_{\text {cond }}+h_{\text {conv }}\right)}{h_{f}+h_{\text {cond }}+h_{\text {conv }}} \approx h_{\text {cond }}+h_{\text {conv }}$

The primary difference between MELCOR condensation model and the diffusion model discussed in previous sections comes down to the type of heat transfer correlation: Churchill-Chu correlation and McAdams correlation. For most of Anderson's experiments where Rayleigh number sits between $10^{9}$ and $10^{10}$, both correlations can be considered but MELCOR uses linear interpolation of the aforementioned equations for laminar and turbulent cases. At such condition, Nusselt number predicted by McAdams correlation, and therefore the condensation heat transfer rate directly proportional to the Nusselt number, is significantly larger than that by Churchill-Chu correlation as shown in Fig. 5.

\section{Results}

\subsection{Nodalization-dependent predictions of MELCOR}

It was postulated that the nodalization-dependent predictions of MELCOR outlined by Fu (2015) is due to using node size as the characteristic length scale and the length scale-dependent models that MELCOR uses. This is not considered appropriate. To evaluate this, the original MELCOR model for condensation was assessed with physical plate length as the characteristic length scale input as shown in Fig. 6. With MELCOR's original model that is length scale-dependent (Churchill-Chu correlation), the 
predictions are no longer nodalization-dependent if physical length of the plate is used for characteristic length scale.

The length scale-dependent characteristics of MELCOR's original condensation model is also illustrated in Fig. 7. The predicted HTC decreases with increasing length scale due to the $\mathrm{L}^{-1 / 4}$ term from the laminar case length scale-dependent expression. MELCOR simulations with various nodalizations using node size as the characteristic length scale agree with the length scale-dependent trend of ChurchillChu correlation. By examining the model, it was observed that the predictions with grid nodalization using node size length scale, while seemingly reasonable, are based on inappropriate use of characteristic length scale input.

Fu's results indicated that the HTC increases as the nodalization becomes finer. This agrees well with the previously discussed characteristics of Churchill-Chu correlation. The node size is always smaller than the physical length scale of the geometry because the overall physical space is subdivided to create a set of control volumes in the computational domain. As finer nodalizations are used, the predicted HTC with node size as the characteristic length scale increases simply because the correlation is dependent of the $\mathrm{L}^{-1 / 4}$ term. MELCOR predictions with other nodalizations with node size as the characteristic length scale input reinforces this notion by providing an overestimation at even finer nodalizations. Therefore, it is reasonable to observe that the correct use of the characteristic length scale input as a physical length scale of the geometry provided nodalization-independent, but underestimated, HTC predictions.

MELCOR requires characteristic length scale input in order to calculate dimensionless numbers such as the Reynolds, Grashof, Nusselt, Sherwood numbers, etc. (Gauntt, 2005). Considering this use of characteristic length scale input, it is physically more appropriate to use physical length scale of the defined problem geometry, not the node sizes of individual control volumes.

\subsection{Implementation of modified model}


The use of more appropriate characteristic length scale guarantees nodalization-independent results for all nodalizations. However, the nodalization-independent results using the original MELCOR model are still underpredicted. The diffusion model discussed in section 4.2 provides predictions within the uncertainty range of the HTC measurements. McAdams correlation also has the advantage of being independent of the characteristic length scale (Chapman, 1984). This length scale-independent model was implemented in MELCOR to replace the original Churchill-Chu correlation in an effort to deal with the underpredicting-tendency and nodalization-dependence of MELCOR's original condensation model.

Fig. 8 shows MELCOR prediction of HTC for the complete set of atmospheric tests by Anderson (1998) with the newly implemented model. The McAdams correlation provides substantially better agreements between the predicted values and the experimental data. The predictions, while lower than the measured data, are within or near the uncertainty margins of the measurements indicating the validity of the model. For relatively higher HTC cases, which corresponds to higher steam fraction conditions, the predictions generally show better agreements with the test data as shown in Fig. 8 and 9. The results indicate that the model is more credible with higher steam molar fraction conditions: with steam fraction higher than about 0.58 , the predictions are within the uncertainty margins of the experimental measurements. Nevertheless, the predictions are generally acceptable for lower steam fraction cases as well. MELCOR with our implemented model always provides significantly better predictions than the original model. Also, the predicted heat removal rates are still underpredicted and thus provides conservative predictions for postulated gas-steam mixture conditions.

\section{Conclusions}

The reported nodalization-dependence of MELCOR predictions was investigated. Length scaledependent condensation model and use of node size as the characteristic length were considered as the potential cause of the issue. It was confirmed that, upon using the physical length of the plate as the characteristic length scale, the predictions are no longer nodalization-dependent. As a result, more 
appropriate use of characteristic length scale that better describes the physics of the defined problem was suggested.

Correct use of characteristic length scale provides nodalization-independent results but MELCOR still underpredicts the overall HTC. To address the underpredicting-tendency, MELCOR convective heat transfer model based on which the condensation rate is determined (Churchill-Chu correlation) was compared with McAdams correlation. At the boundary where the laminar natural convection regime starts to turn turbulent $\left(\mathrm{Ra} \sim 10^{9}\right)$, the McAdams correlation predicts higher HTC, as well as providing length scale-independent predictions (Chapman, 1984). To resolve the underpredicting-tendency, McAdams correlation was implemented in MELCOR. MELCOR with the implemented model was then validated against Anderson's atmospheric experiment (1998). Simulations with modified model showed improvements in predictions of about $55 \%$ on average for Rayleigh numbers in the order of $10^{9}$ and $10^{10}$.

Although better improvements were expected, the predictions for Anderson's experiments with our implemented model are always below 30\% error margin. Especially for cases with steam fraction lower than about 0.58 , the error is on or below the uncertainty margin of the experimental measurements (15\%). This trend of decreasing error with increasing steam fraction is under investigation. Also, it was observed that even though the new model predicts significantly higher heat transfer, the HTC is always underpredicted compared to the experimental data for the gas-steam mixture, implying that conservative predictions are provided.

The implemented model is only for flat plate geometry and so was validated only against vertically oriented flat plate experiments. For other geometries, MELCOR uses different correlations to calculated convective heat transfer which directly affects the computation of mass transfer. Our future investigations focus on conditions with other orientations (horizontal downward facing) and in other geometries such as condensation on tube. Additionally, the model can be improved to produce better predictions for lower steam content scenarios to offer wider range of applications. 


\section{Nomenclature}

$\begin{array}{ll}A & \text { Area }\left(\mathrm{m}^{2}\right) \\ B & \text { Dimensionless mass fraction difference } \\ C_{p} & \text { Heat capacity }(\mathrm{J} / \mathrm{kg}-\mathrm{K}) \\ D & \text { Diffusion coefficient }\left(\mathrm{m}^{2} / \mathrm{s}\right) \\ g & \text { Gravitational acceleration }\left(\mathrm{m} / \mathrm{s}^{2}\right) \\ H & \text { Specific enthalpy }(\mathrm{J} / \mathrm{kg}) \\ h & \text { Heat transfer coefficient }\left(\mathrm{W} / \mathrm{m}^{2}-\mathrm{K}\right) \\ j & \text { Mass transfer coefficient }(\mathrm{m} / \mathrm{s}) \\ k & \text { Thermal conductivity }(\mathrm{W} / \mathrm{m}-\mathrm{K}) \\ L & \text { Characteristic length scale }(\mathrm{m}) \\ \dot{m} & \text { Mass flux }\left(\mathrm{kg} / \mathrm{m}^{2}-\mathrm{s}\right) \\ P & \text { Pressure }(\text { bar }) \\ R & \text { Thermal resistance per unit area }\left(\mathrm{m}^{2}-\mathrm{K} / \mathrm{W}\right) \\ q^{\prime \prime} & \text { Heat flux }\left(\mathrm{W} / \mathrm{m}^{2}\right) \\ T & \text { Temperature }(\mathrm{K}) \\ \dot{V} & \text { Volumetric flow rate }\left(\mathrm{m}^{3} / \mathrm{s}\right) \\ X & \text { Mole fraction } \\ Y & \text { Mass fraction }\end{array}$

Greek letters

$\Gamma \quad$ Mass flowrate of condensate per unit width $(\mathrm{kg} / \mathrm{m}-\mathrm{s})$

$\Delta \quad$ Difference in appropriate quantity

$\delta \quad$ Condensate film thickness (m)

$\mu \quad$ Dynamic viscosity $(\mathrm{kg} / \mathrm{m}-\mathrm{s})$

$\rho \quad$ Density $\left(\mathrm{kg} / \mathrm{m}^{3}\right)$

$\theta \quad$ Suction factor

Superscripts

* Without the consideration of appropriate correction factor

Subscripts

avg Averaged 


$\begin{array}{ll}b & \text { Bulk } \\ c & \text { Coolant } \\ \text { CEB } & \text { CEB method } \\ \text { cond } & \text { Condensation } \\ \text { conv } & \text { Convection } \\ \text { exp } & \text { Experimental } \\ f & \text { Condensate film } \\ \text { guess } & \text { Initial guess value } \\ H & \text { Horizontal plate } \\ H F M & \text { HFM method } \\ i & \text { Interface } \\ l & \text { Liquid } \\ n & \text { Noncondensable gas (air) } \\ \text { sim } & \text { Simulation } \\ V & \text { Vertical plate } \\ v & \text { Vapor (steam) } \\ w & \text { Wall }\end{array}$

Nondimensional Numbers

$G r \quad$ Grashof number

$\mathrm{Pr} \quad$ Prandtl number

$R a \quad$ Rayleigh number

Re Reynolds number

Sc Schmidt number

Sh Sherwood number 


\section{Acknowledgments}

Funding for this project was provided by the DOE Nuclear Engineering University Program (NEUP). 


\section{Tables and Figures}

Table 1. Experimental and simulation steady states for Anderson's experiment (1998)

Figure 1. Nodalization of test vessel; (a) one-volume near condensing walls, (b) 6 by 6 grid; dimensions in meters

Figure 2. Simulated pressure and temperature for Test 202

Figure 3. Rayleigh numbers for Anderson's experiments (1998)

Figure 4. (a) Schematic view of film-wise condensation, (b) representation of heat transfer resistance coupling; $\mathrm{R}=1 / \mathrm{h}$

Figure 5. Comparison of heat transfer correlations around critical Rayleigh number $\left(10^{9}\right)$; shaded region for experimental conditions

Figure 6. HTC predictions with varying characteristic length scale; ○, Fu (2015).

Figure 7. Nodalization-dependence of MELCOR's original condensation model, Test 219; •, Fu (2015)

Figure 8 . HTC predictions by MELCOR; $15 \%$ uncertainty margins

Figure 9. Error of MELCOR prediction with experimental data 
Table 1. Experimental and simulation steady states for Anderson's experiment (1998)

\begin{tabular}{|c|c|c|c|}
\hline Test & $\mathrm{P}_{\text {sim,avg }}(\mathrm{Pa})$ & $\mathrm{T}_{\text {b,exp }}(\mathrm{K})$ & $\mathrm{T}_{\text {b,sim,avg }}(\mathrm{K})$ \\
\hline 202 & 100,102 & 333.80 & 333.54 \\
\hline 203 & 100,326 & 342.38 & 342.23 \\
\hline 204 & 100,763 & 342.19 & 341.86 \\
\hline 211 & 100,598 & 341.30 & 341.12 \\
\hline 213 & 100,707 & 352.83 & 352.55 \\
\hline 215 & 104,810 & 358.27 & 357.82 \\
\hline 216 & 104,320 & 358.40 & 357.94 \\
\hline 217 & 102,977 & 357.70 & 357.34 \\
\hline 218 & 100,668 & 362.68 & 362.35 \\
\hline 219 & 98,367 & 362.87 & 361.77 \\
\hline 220 & 100,351 & 362.83 & 362.35 \\
\hline 326 & 101,497 & 354.61 & 354.45 \\
\hline 328 & 101,278 & 353.95 & 353.82 \\
\hline 329 & 99,615 & 353.73 & 353.17 \\
\hline
\end{tabular}


1

2

3

4

5

6

7

8

9

10

11

12

13

14

15

16

17

18

19

20

21

22

23

24

25

26

27

28

29

30

31

32

33

34

35

36

37

38

39

40

41

42

43

44

45

46

47

48

49

50

51

52

53

54

55

56

57

58

59

60

61

62

63

64

65
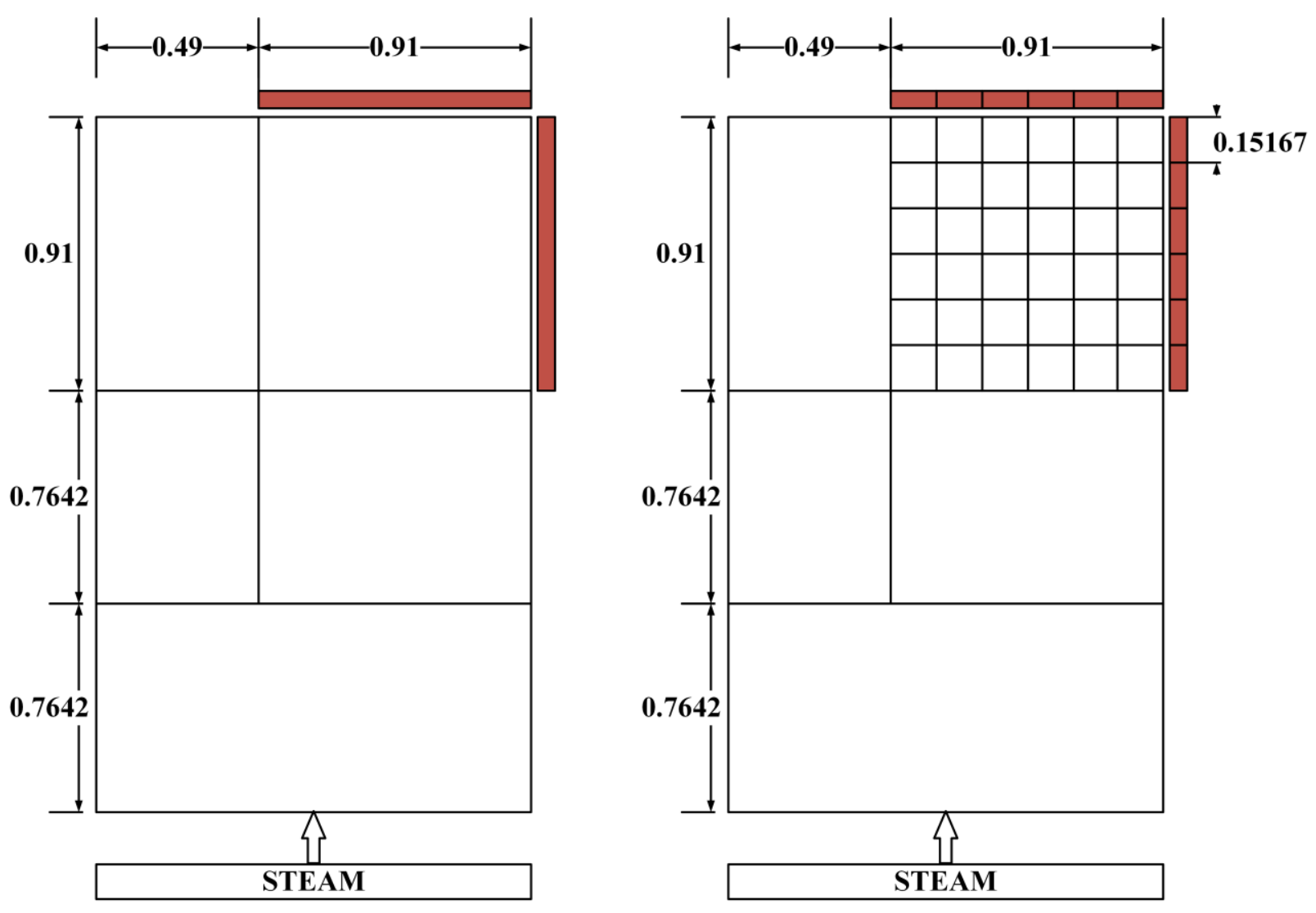

Fig. 1. Nodalizations of test vessel; (a) one-volume near condensing walls, (b) 6 by 6 grid; dimensions in meters 


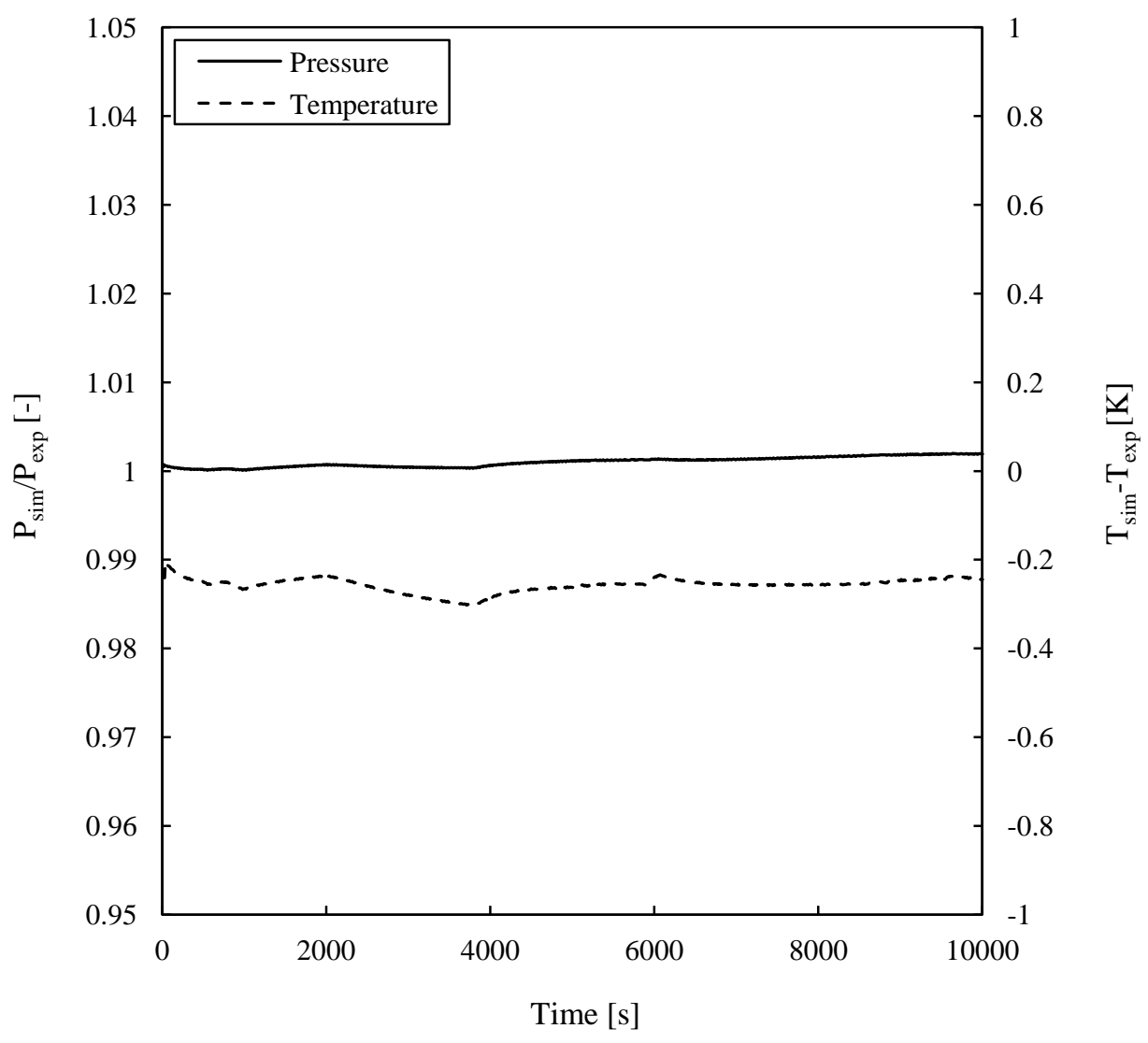

Fig. 2. Simulated pressure and temperature for Test 202 


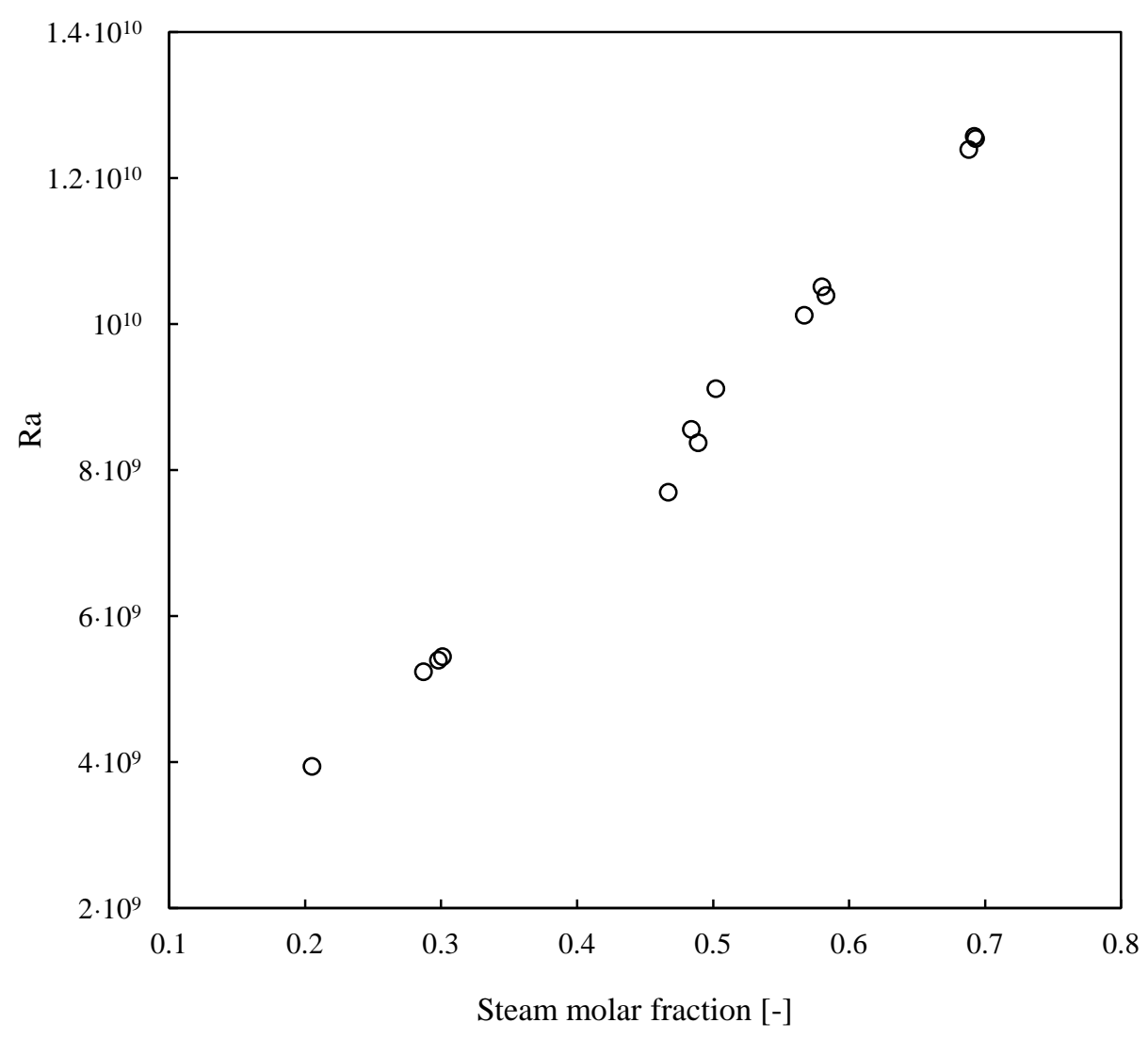

Fig. 3. Rayleigh numbers for Anderson's experiments (1998) 

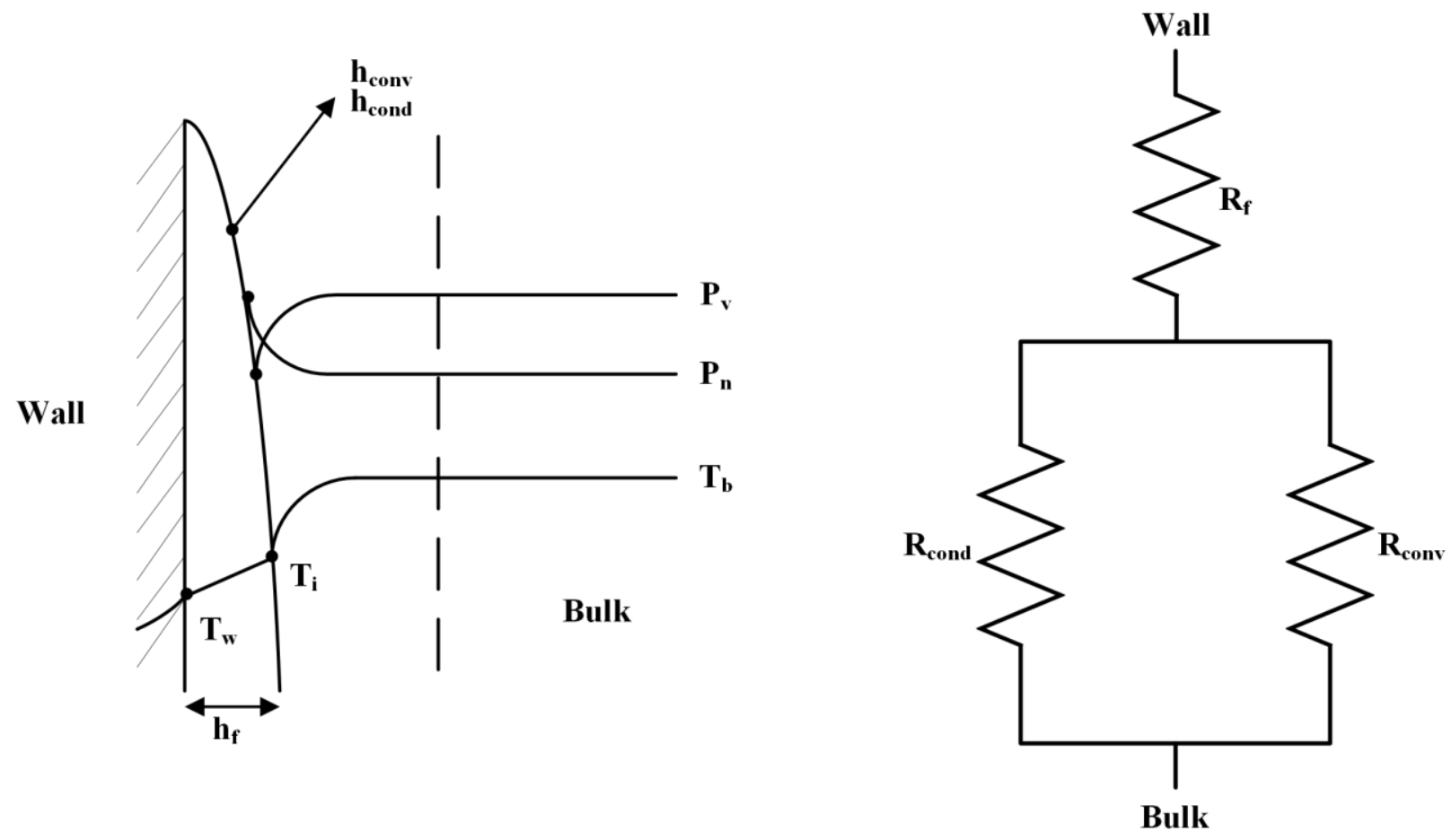

Fig. 4. (a) Schematic view of film-wise condensation, (b) Representation of heat transfer resistances coupling; $R=1 / \mathrm{h}$ 
Fig. 5. Comparison of heat transfer correlations around critical Rayleigh number $\left(10^{9}\right)$; shaded region for experimental conditions 


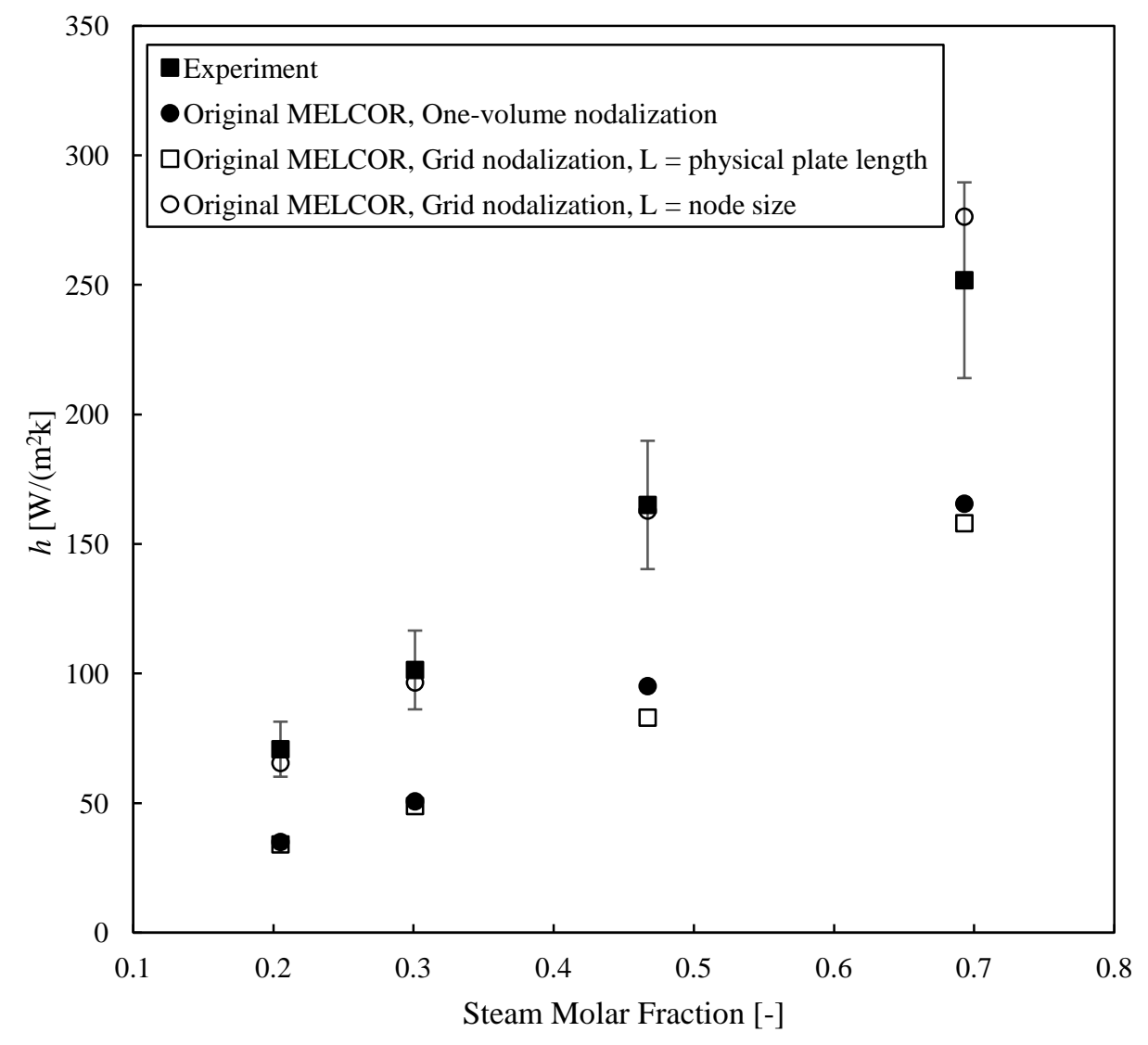

Fig. 6. HTC predictions with varying characteristic length scale; ○, Fu (2015) 


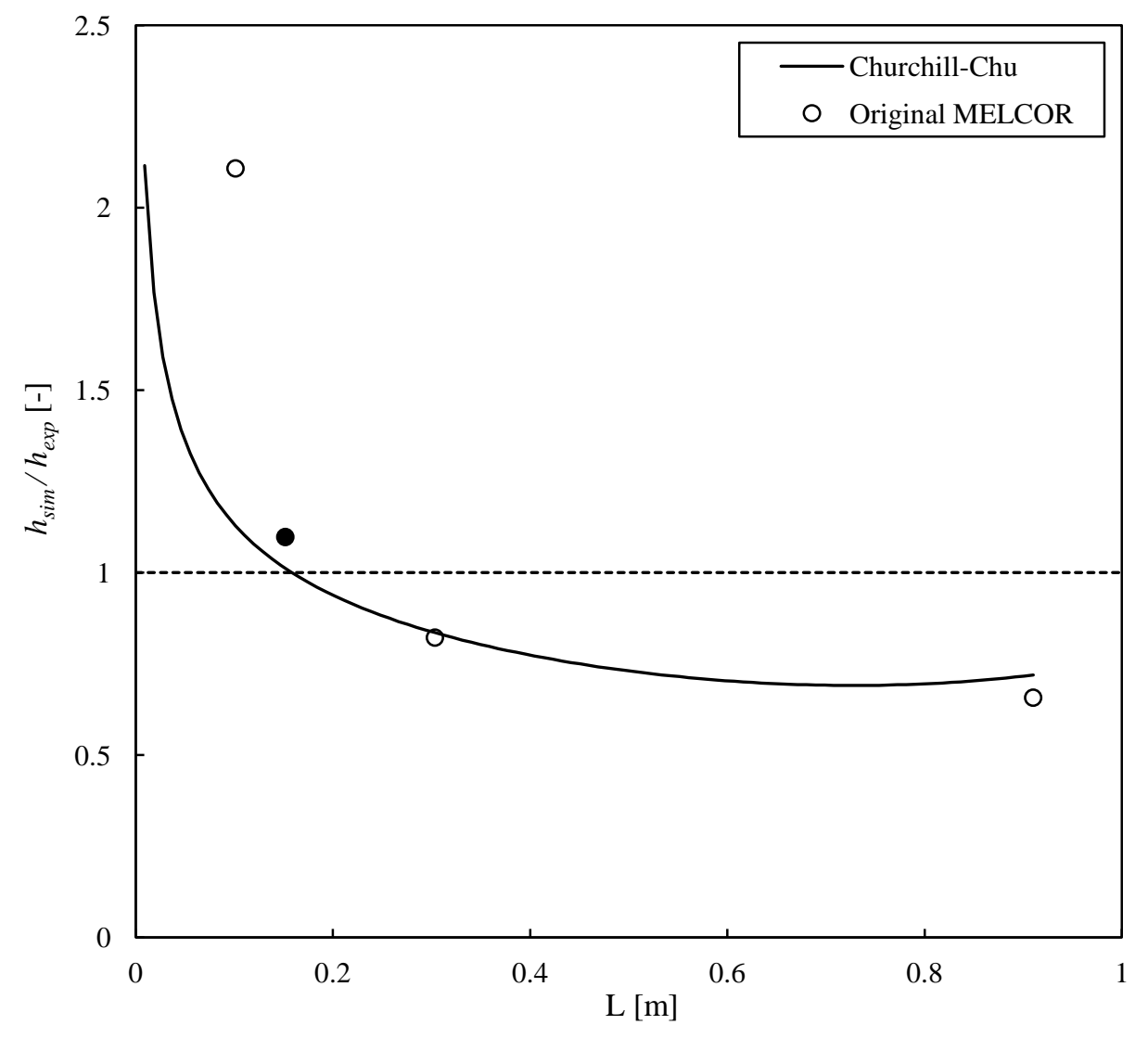

Fig. 7. Nodalization-dependence of MELCOR's original condensation model, Test 219; •, Fu (2015) 


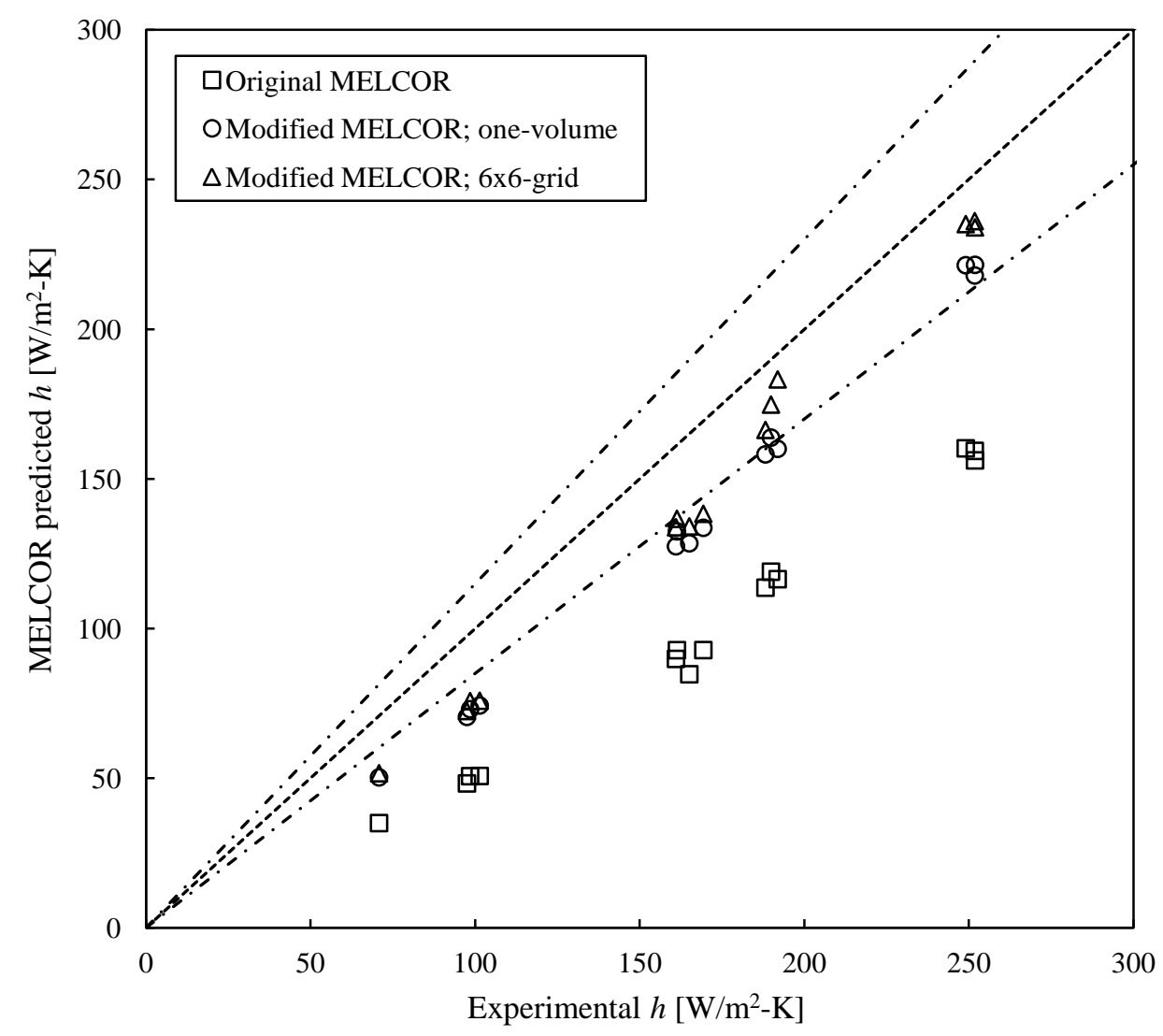

Fig. 8. HTC predictions by MELCOR; $15 \%$ uncertainty margins 


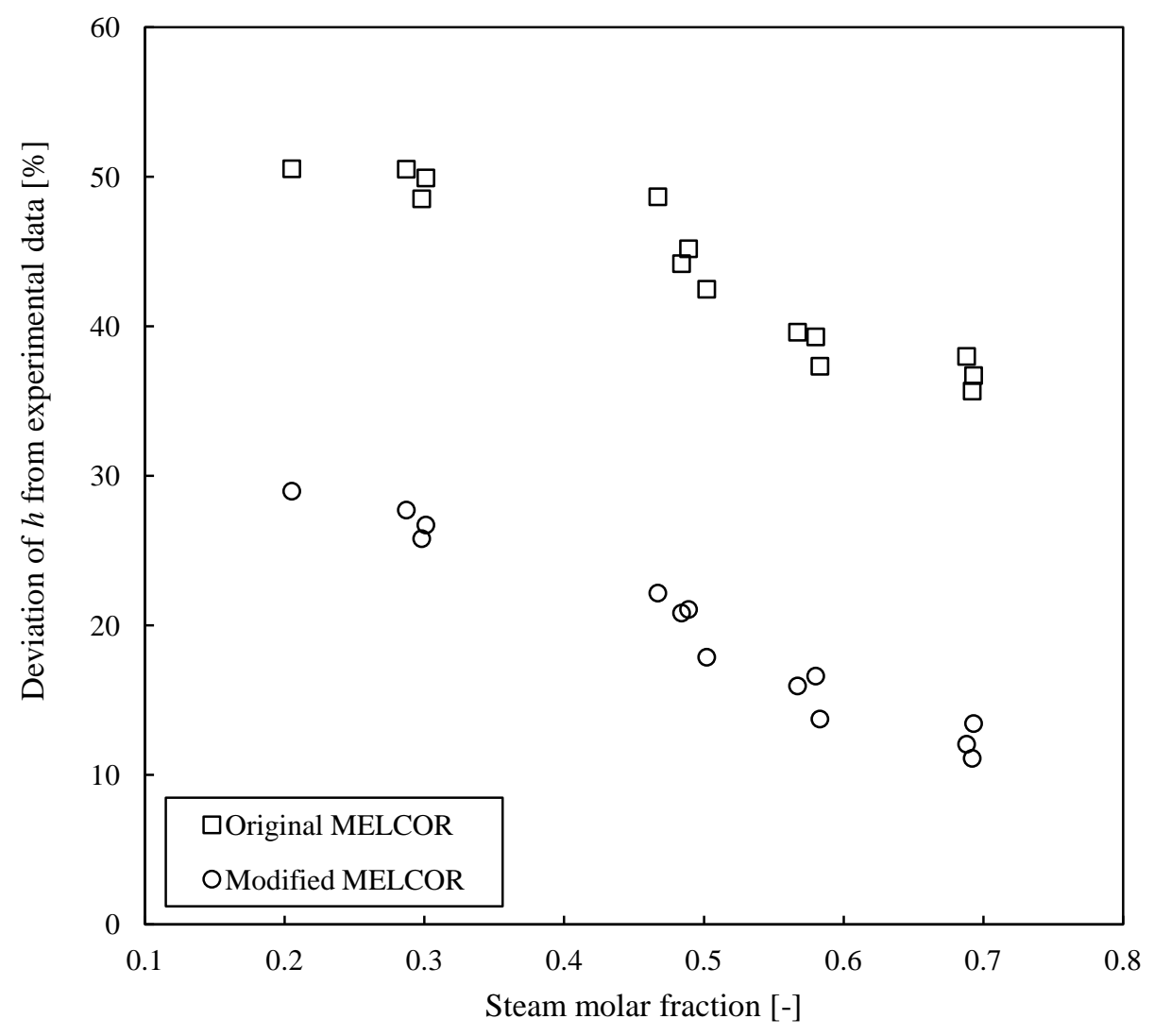

Fig. 9. Error of MELCOR prediction with experimental data 


\section{References}

Ambrosini, W., Forgione, N., Manfredini, A., Oriolo, F., 2006. On various forms of the heat and mass transfer analog: Discussion and application to condensation experiments. Nucl. Eng. Des. 236. 1013-1027.

Anderson, M. H., 1998. Steam condensation on cold walls of advanced PWR containments. PhD Thesis, University of Wisconsin, Madison, 1998.

Anderson, M. H., Herranz, L. E., Corradini, M. L., 1998. Experimental analysis of heat transfer within the AP600 containment under postulated accident conditions. Nucl. Eng. Des. 185, 153-172.

Bird, R. B., Steward, W., Lightfoot, E., 2002. Transport Phenomena. John Wiley and Sons, New York.

Chapman, A. J., 1984. Heat Transfer. Macmillan, New York.

Chilton, T. H., Colburn, E. I., 1934. Mass Transfer (Absorption) Coefficients: Prediction from Data on Heat Transfer and Fluid Friction. Ind. Eng. Chem. 26. 1183-1187.

Corradini, M. L., 1983. Turbulent condensation on a cold wall in the presence of a noncondensable gas. Nucl. Tech. 64, 186-195.

Fu, W., Yoon, D., Corradini, M. L., Anderson, M. H., 2015. Assessment of the MELCOR and RELAP53D code for condensation in the presence of noncondensable gas. International Topical Meeting on Nuclear Reactor Thermal Hydraulics 2015, NURETH 2015, vol. 8

Gauntt, R. O., Cash, J. E., Cole, R. K., Erickson, C. M., Humphries, L. L., Rodriquez, S. B., Young, M. F., 2005. MELCOR computer code manuals. NUREG report, U.S. NRC, NUREG/CR-6119. 
Herranz, L. E., Anderson, M. H., Corradini, M. L., 1998. A diffusion layer model for steam condensation within the AP600 containment. Nucl. Eng. Des. 183. 133-150.

Hogan, K., Liao, Y., Beeny, B., Vierow, K., Cole, R. Jr., Humphries, L., Gauntt, R., 2010. Implementation of a generalized diffusion layer model for condensation into MELCOR. Nucl. Eng. Des. 240, 3202-3208.

Kim, M. H., Corradini, M. L., 1990. Modeling of condensation heat transfer in a reactor containment. Nucl. Eng. Des. 118, 193-212.

Kutateladze, S. S., Gogonin, I. I., 1979. Heat transfer in film condensation of slowly moving vapour. Int. J. Heat Mass Transf. 22. 193-1599.

Liao, Y., Vierow, K., 2007. A generalized diffusion layer model for condensation of vapor with noncondensable gases. J. Heat Transf. 129. 988-994.

Nusselt, W. A., 1916. The Surface condensation of Water Vapor. Zetrschr. Ver. Ing. 60, 541-546.

Othmer, D. F., 1929. The condensation of steam. Ind. Eng. Chem. 21, 576-583

Peterson, P. F., Schrock, V. E., Kageyama, T. Diffusion layer theory for turbulent vapor condensation with noncondensable gases. Trans. ASME. 115. 998-1003.

Rohsenow, W. M., Choi, H., 1961. Heat, Mass and Momentum Transfer. Prentice-Hall, New Jersey. 
Rosa, J. C., Herranz, L. E., Munoz-Cobo, J. L., 2009. Analysis of the suction effect on the mass transfer when using the heat and mass transfer analogy. Nucl. Eng. Des. 239, 2042-2055.

Slaughterbeck, D. C. 1970. Review of heat transfer coefficients for condensing steam in a containment building following a loss-of-coolant accident. IN-1388, Idaho Nuclear Corp.

Sparrow, E. M., Lin, S. H. 1964. Condensation heat transfer in the presence of a noncondensable gas. J. Heat Transfer. 86. 430-436. 